Kohl: a Journal for Body and Gender Research

Vol. 6, No. 3 (Winter 2020)

\title{
Transgender Visibility/Invisibility: Navigating Cisnormative Structures and Discourses
}

Sophia Sherif 
Trans is becoming more visible in current western discourses around gender, in the public sphere as well as in the media. As a transgender person myself, I am an insider to this community in Egypt, and I have always been alienated from the discourses that were supposed to tackle trans issues. In the collective Egyptian consciousness, transness is still believed to be a foreign phenomenon, along with other phenomena that the mainstream Egyptian society does not want to deal with like homosexuality and sex work. By alienating what it does not want to face, the mainstream claims moral purity and superiority in an era where there is so much anxiety surrounding the so-called "national identity" due to different political and economic challenges and hindrances. Consequently, vulnerable and marginalized communities navigate these social and political structures set against them. This question is not about juxtaposing people's narratives with structures they have always found alien to themselves, but about telling stories of resilience, survival, solidarity, and collective healing. An inquiry that occupies me, literally and conceptually, is transgender (in)visibility in a highly oppressive context where one's existence is criminalized, pathologized, or at least ignored. What are the ways, performances, and networks that trans people form or create to navigate discrimination and marginalization? How do trans people experience this ongoing dialectical and social tension between their own identities and the ones imposed by society, disregarding their rights to self-determination? Upon researching these questions, I was struck by the scarcity of academic and ethnographic literature on trans issues. Most of the literature available on visibility relies heavily on gay, lesbian, and bisexual narratives that do not reflect the lived experiences of trans people. Transgender studies is still a new and emerging field, but it is still western-centric, and most of the sources on transness in the "Middle East" are concerned with the Iranian context. It is my hope to contribute to decolonizing and decentralizing transgender studies and archives.

\section{Methodological Question(ing)}

In Unfinished: The Anthropology of Becoming, João Biehl and Peter Locke (2017) discuss what they call ethnographic sensorium:

These moments and stories are incomplete views onto subjects and lifeworlds in the process of becoming. Taken together, they make up an ethnographic sensorium: a multifaceted and affective point of contact with worlds of inequality, hovering on the verge of exhaustion while also harboring the potential for things to be otherwise. (p.3)

I believe this plasticity to be crucial for looking into trans people's narratives and experiences, for transness is a continuous state of becoming, changing, and maturing. The experience of becoming is not only related to the experience of self-identification or coming to terms with one's own identity, but rather as "feeling like the ground beneath one's feet is changing," as one collaborator described.

As an insider to the transgender community in Egypt, it was hard for me to define the field, draw its boundaries, and give it rigid borders. This is also what made my methodology trans. My interactions as a "researcher" with "participants" felt more like friendly, casual interactions and reflections between friends or 
people sharing similar experiences. Ethnography, even intimate auto-ethnography, asks a certain distance of us, so our experiences become familiar and unfamiliar at the same time. I organized a gathering with four other trans women at different phases of our transitioning process at a bar in Maadi, Cairo. I was intending for the meeting to be a "participant observation" where I would take note of our interactions, interests, connections, and disconnections, among ourselves and with our surroundings. By trying to observe how we as trans people exist and interact in public sphere, I myself became a subject like the rest of the participants. I then sat individually with four trans people from different backgrounds in what I was envisioning as structured interviews. Their subjectivities emerged in constant states of flux, movements, and change. At some point, I realized that my positionality as an Egyptian trans person was what made these encounters possible, heartwarming, and open. From participants, they became collaborators. Their names have been changed according to their choice and consent.

\section{(In)visibility Politics}

Vivian is only 20-years-old; she identifies as a queer non-binary trans woman. She passes, as she is socially read as a woman, yet she prefers to adopt a butch expression in her style and clothing:

Visibility is strength and power and over the years, it has given me pride in my own identity. I mean cis heterosexuals would not second guess my identity most of the time, unless I am dealing with people who have to see my ID, which can end badly, but so far the worst has been the negative impact on my mental health. I love my visibility when I am around queer people; I am truly seen for who I am: a butch queer transwoman. I feel I am acknowledged and it feels really amazing.

I asked Mai, a 26-years-old straight trans female, about visibility and what it meant for her:

The experience varied greatly across time. I have always been feminine and expressed myself in a feminine way. I went to a private school and university and most of the time I would dress as unisex. After college, I started to pass and dress more and more the way I wanted and everything fell into place.

While Vivian felt she belonged in the queer community because of their acknowledgment of her butchness, Mai was slowly integrating herself into the mainstream society by performing gender in a conformist fashion

- "a straight female," as she describes herself. Since they both pass as women, they are more confident and assertive in public. This does not mean that trans people's desire for visibility is present in the same way, if at all. Tara, who identifies as a pansexual trans woman, recalls how her decision to transition affected her life drastically. She cut ties with a lot of people and circles because she could no longer deal with being systematically misgendered or gossiped about, including in family circles. She felt stranded in the middle of nowhere, not knowing what the future had in store for her. However, her work gives her a sense of stability that helps her support herself. 
Biehl and Locke (2017) argue that "ethnographic inquiry brings us closer to the world's matters of fact and people's simultaneous movements away from and toward material structures and relational fields" (p.5). From the ethnographic data I collected with the various collaborators, it became clear that transitioning, seen as a "phase" when one does not reach the state of passing, can force trans people to hide their identity in order to avoid harassments and expected violence. Nouran, who identifies as a trans woman in transition and selfexploration, says that she used to be more closeted. Playing around her androgynous looks, she avoids confrontations with society by choosing her clothes and colors in a moderate way. However, she considers having benefitted from the change in the style and fashion, as these became more androgynous, especially after the revolution. This helped her keep and sustain part of the feminine side that she does not want to lose. On the other hand, Tara who is also in her transition journey, says that she acts serious in public, presenting a stoic façade. She opts for baggy and loose clothes to hide the physical changes from hormone replacement therapy (HRT), and prefers to take Ubers instead of public transportation, where she get stares and feels violated. By looking into different transgender narratives at different moments and locations, it becomes clear that issues of (in)visibility are neither static, nor do they follow a similar/linear trajectory; rather, they change and evolve according to the flows and ruptures of trans people's lived experiences.

\section{Experiencing and Doing Gender}

During our bar encounter in Maadi, Cairo, we asked a trans woman who was close to passing whether she would consider actually going out as a woman. She was happy with our remarks but expressed her anxiety at doing so because of her voice. She believed her voice is what we in the transgender community would call "a tell" - an aspect that would make a trans woman visible as trans like the arms, shoulders, male pattern baldness, or voice. Although some cisgender (non-transgender) women have some of these tells, it becomes more of an insecurity and a trigger for transwomen in specific because of dysphoria and personal security and safety. For this collaborator, her voice was a trigger for both. She had tried to find online trainings to feminize it but these were entirely in English and she could not find such resources in Arabic. With these absences, ruptures, and instances of violence being structural and institutionalized, trans people doing and perceiving gender cannot be viewed in a vaccum, regardless of how visible they might be. Transness is not an internal psychological process; it is socially embedded, ongoing, and governed by many socio-political factors (Johnson \& Hull 2018).

Our first encounter with gender dysphoria starts at an early age; yet, it can remain incomprehensible for years. Vivian reflects on her school experience:

When it comes to school I was always an outcast. I was really young, confused, didn't understand the first thing about gender and sexuality. Did not know what I was, but I always knew I was not what everyone thought I was. I felt dysphoric most of the time until I had a mental break down and was diagnosed with bipolar disorder and psychosis and got treated for it. A while after I discovered my identity and had a feeling that dysphoria was just fuel to the fire when it comes to my mental health issues. 
Tara tells another traumatic story: in middle school, she was outed as a queer person. As a result, school supervisors forced her to undress as part of the punishment and humiliation. She became an outcast for the duration of her scholarly experience. Nouran describes her experience with dysphoria as very stressful and difficult to handle. For her, it was the driving force that overrode any other consideration. She couldn't interact with people, think of work or future plans, or even have romantic encounters, and this did not stop until she started her HRT. Thus, experiencing dysphoria is not just a psychological process; it is indivisible from sociability and social life for the majority of trans people who experience it.

\section{Socio-Political Influences}

Nouran talks about her work experience as a freelance artist. She chose freelance work because of dysphoria. For many trans people in Egypt, the fear of people and social interactions can lead to either confrontation, and paying the price for it, or isolation. Nouran wonders if she will ever seek a startup or a fixed job, but it will most probably be with other queer people. Mai, on the other hand, jokingly said, "maybe I am not the right person for this conversation," before bursting out laughing. Mai doesn't need to work for money; her parents are accepting and help her with all things finances. She also gets a comfortable income from her Instagram page, which is a sort of influencer page about fashion and beauty. Social class and family acceptance and support are influences that can drastically change trans experience. Vivian speaks about both her university and work experiences:

When it comes to uni I have not actually started my academic studies yet. I encountered a problem when I first got into Cairo university, Faculty of Arts. I wanted to study human sciences and I wanted to get into the sociology or anthropology program but I didn't get accepted, and not even because I failed the interview. They did not interview me. They saw my ID card and how I looked and how the two mismatched and they panicked. The head of the sociology department had problems with me studying that program because he said he could not take responsibility for anything that might happen to me. When it comes to work, my experience has been great honestly. In 2017, I got my first real job volunteering as a translator in the first fully trans-run organization in the region. We worked on knowledge production through a platform we created with the aim of raising awareness about trans issues in Arabic. I still work there now. In 2019, I found work in something related to what I wanted to study: a researcher on an oral history documentation project that documents life and human experiences of the queer community.

Although Vivian had neither the acceptance and support of her family nor the financial resources to study at a private university that would allow her in, she managed to pave her way through working and engaging with preexisting, underground, and newly emerging organizations working for the LGBTQIA+ community in the region. She was supported by what Bourdieu calls cultural capital (Huang 2019), which, in this case, is her mastery of foreign languages, exposure to social justice issues and debates internationally, and social capital 
in the form of connections and friendships with queer and feminist people who work mostly underground in the region.

When talking about legal recognition, trans people in Egypt could either go to private doctors and pay, or see less professional doctors and psychologists who follow up with them for at least two years before giving them a medical report that would be recognized by the government. Mai talks about her experience to get legal recognition:

It was a long long and stressful journey and in my case it was all about pay pay pay. I was followed by two doctors, one in Alexandria for a year, and another in Cairo for a year and a half. They were professional yet pricey and the sessions were very long and stressful but it was fruitful and worth it at the end.

Nouran experience was more diverse with psychiatrists:

I went to really a lot of psychiatrists - private ones and at el Hussein governmental hospital. The doctors in el Hussein were the worst, I could not benefit from them. However, one private doctor tried to hypnotize me as a form of conversion therapy to make me forget about my transness. I finally managed to get a medical report from a pricey private doctor and used the report to go to the endocrinologist. I am planning to see other doctors for the sex reassignment surgery.

Talking about the interactions between psychiatrists in Egypt and trans individual requires its own research. I am merely reflecting on the socio-political challenges and atmosphere that trans people have to navigate in order to reach legal recognition and maintain security.

As a transgender person I believe we are constantly facing attempts to get erased. The constant, rigid policing of gender socially, politically, and economically makes it easier to pretend as if we are not there, especially in locations where we are actively pushed out of the collective consciousness. In Egypt, we can achieve legal recognition through a strict and long bureaucratic chain of procedures while still not existing in the political and social collective awareness. We still get punished and regulated in terms of how we do gender, not only from the government institutions and authorities, but also from society as a whole. Consequently, the narratives of trans people can be considered a form of resistance to the initial premise that we do not exist, or that our existence is a form of perversion. This ethnographic exercise sought narratives, stories, and discourses that are in flux and constantly evolving to form an ethnographic sensorium. I bypassed the lack and scarcity of relevant literature by treating transgender experiences - our experiences - as primary and legitimate data. 


\section{References}

Brumbaugh-Johnson, S. M., \& Hull, K. E. (2019). Coming out as transgender: Navigating the social implications of a transgender identity. Journal of Homosexuality, 66(8), 1148-1177.

Biehl, J., \& Locke, P. (2017). Unfinished: The Anthropology of Becoming Durham: Duke University Press.

Huang, X. (2019). Understanding Bourdieu - Cultural Capital and Habitus. Review of European Studies, 11(3), 45-49. 